\title{
Characterization and Outcome of Patients Presented with Unilateral Nasal Disease to ENT unit at Hillah, Iraq
}

\author{
Safaa Hussain Alturaihy \\ M.B.Ch.B./F.I.B.M.S. ENT/Assistant Professor/Department of Surgery/College of Medicine/Babylon University/ \\ Consultant ENT in Hillah General Teaching Hospital at Department of Surgery
}

\begin{abstract}
Background: A common finding during daily otolaryngological practice is a patient with unilateral nasal symptoms, nasal polyp or mass. The causes behind most cases of unilateral nasal disorder are inflammatory in nature and responds well to medical intervention and rarely there is need for surgical management. The possibility of neoplastic nature is high when there is unilateral nasal complaint or pathology as neoplastic conditions during their early stages may mimic inflammatory pathologies.
\end{abstract}

Aim of the Study: The aim of the current study was to highlight the causes of unilateral nasal disease, their most frequent mode of presentation, management strategies and outcome in a sample of Iraqi patients.

Patients and Method: The current prospective study included 96 patients, 42 males and 54 females, with signs and symptoms suggestive of unilateral nasal disease. The study was carried out at Hillah General Teaching Hospital, Babel province, mid-Euphrates region of Iraq and the work with this study has extended from January 2014 to August 2019. All enrolled patients were subjected to routine ENT examination and office flexible endoscopy. Patients were managed by functional endoscopic sinus surgery for purpose of excisional or incisional biopsy.

Results: The current study included 96 patients with a mean age of $49.09 \pm 7.43$ years and an age range of 39 to 67 years. There were 42 males and 54 females. The results of complete evaluation have shown the following pathologies at the end of the study: nasal polyposis $(31,32.3 \%)$, chronic rhinosinusitis without polyp (16, $16.7 \%)$, antrochoanal polyp $(14,14.6 \%)$, inverted papilloma $(11,11.5 \%)$, frontoethmoidal mucocele $(7$, $7.3 \%)$, concha bullosa $(4,4.2 \%)$, squamous cell carcinoma $(3,3.1 \%)$, rhinolith $(2,2.1 \%)$, fibrous dysplasia $(2,2.1 \%)$, adenocarcinoma $(2,2.1 \%)$, malignant melanoma $(1,1.0 \%)$, cavernous hemangioma $(1,1.0 \%)$, pyocele in concha bullosa $(1,1.0 \%)$ and non Hodgkin's $(1,1.0 \%)$. Therefore, in the current study, nasal polyposis was the commonest cause of unilateral sinonasal disease followed by chronic rhinosinusitis without polyp, antrochoanal polyp and inverted papilloma. The rate of malignant neoplasms was low.

Conclusion: Differentiating the neoplastic nature form non-neoplastic nature of unilateral nasal pathology is the most critical management step and in the current study, nasal polyposis was the commonest cause of unilateral sinonasal disease followed by chronic rhinosinusitis without polyp, antrochoanal polyp and inverted papilloma. The rate of neoplastic malignant conditions was low.

Keywords: Unilateral nasal polyp, Hillah, Iraq.

\section{Corresponding Author:}

\section{Dr. Safaa Hussain Alturaihy}

M.B.Ch.B./F.I.B.M.S. ENT/Assistant Professor/

Department of Surgery/College of Medicine/Babylon

University/Consultant ENT in Hillah General Teaching

Hospital at Department of Surgery

e-mail: alturaihysafaa2@gmail.com

\section{Introduction}

A common finding during daily otolaryngological practice is a patient with unilateral nasal symptoms, nasal polyp or mass ${ }^{1}$. The causes behind most cases of unilateral nasal disorder are inflammatory in nature and responds well to medical intervention and rarely there 
is need for surgical management ${ }^{2}$. The possibility of neoplastic nature is high when there is unilateral nasal complaint or pathology as neoplastic conditions during their early stages may mimic inflammatory pathologies ${ }^{1}$. Actually, the mission of an otolaryngologist is to discover neoplastic conditions in association with unilateral nasal complaint in order to offer the best management options that can assure cure with high rate ${ }^{1}$. Despite the fact that unilateral nasal complaint is a frequent finding in daily clinical practice, literature dealing with the characterization and outcome of these conditions is relatively scanty ${ }^{1,4-6}$.

Unilateral nasal discharge, nasal congestion and nose bleeding in addition to dysosmia, migraine, and facial swelling are most common presenting clinical complaints in patients with unilateral nasal disease (79). Clinical characterization of a patient complaining of single-sided nasal symptoms mass is an essential challenging health issue because they are often accompanied by multifactorial underlying etiology (1, 8 , 9). Evaluation of such health issue should include good history taking, thorough local examination and endoscopic investigation in addition to radiologic evaluation $(1,7)$. Findings on imaging play a significant role in the diagnosis and workup of sinonasal pathology. Bilateral versus unilateral involvement is a key feature that can differentiate between different etiologies (10).

The poverty of national and international publications dealing with clinical presentation and pathologic characterization of unilateral nasal complaint justified the planning and conductance of the current study in Hillah General Teaching Hospital, midEupphrates region of Iraq.

\section{Patients and Method}

The current prospective study included 96 patients, 42 males and 54 females, with signs and symptoms suggestive of unilateral nasal disease. The study was carried out at Hillah General Teaching Hospital, Babel province, mid-Euphrates region of Iraq and the work with this study has extended from January 2014 to August 2019. All enrolled patients were subjected to routine ENT examination and office flexible endoscopy. Patients were managed by functional endoscopic sinus surgery for purpose of excisional or incisional biopsy.
The ethical approval was issued by the ethical approval committee of the local health institute and a verbal consent was obtained from all participants following full illustration of the aim and the procedure of the study. The principal outcomes were the clinical presenting features and the type of pathology.

Data were transformed into SPSS (statistical package for social sciences) software (IBM, Chicago, USA, version 23) for purpose of statistical description. Categorical variables were expressed as number and percentage, whereas, quantitative data were expressed as range, mean and standard deviation.

\section{Results}

The current study included 96 patients with a mean age of $49.09 \pm 7.43$ years and an age range of 39 t0 67 years. There were 42 males and 54 females. The resultsof complete evaluation have shown the following pathologies at the end of the study: nasal polyposis (31, $32.3 \%$, chronic rhinosinusitis without polyp $(16,16.7 \%)$, antrochoanal polyp $(14,14.6 \%)$, inverted papilloma (11, 11.5\%), frontoethmoidal mucocele $(7,7.3 \%)$, concha bullosa $(4,4.2 \%)$, squamous cell carcinoma $(3$, $3.1 \%)$, rhinolith $(2,2.1 \%)$, fibrous dysplasia $(2,2.1 \%)$, adenocarcinoma $(2,2.1 \%)$, malignant melanoma ( 1 , $1.0 \%)$, cavernous hemangioma $(1,1.0 \%)$, pyocele in concha bullosa $(1,1.0 \%)$ and non Hodgkin's $(1,1.0 \%)$. Therefore, in the current study, nasal polyposis was the commonest cause of unilateral sinonasal disease followed by chronic rhinosinusitis without polyp, antrochoanal polyp and inverted papilloma. The rate of malignant neoplasms was low, as demonstrated in figure 1.

The presenting clinical features are shown in figure 2 . The most frequent clinical symptom was nasal obstruction which was seen in 81 cases $(84.4 \%)$, followed by rhinorrhea (69 cases, $71.9 \%$ ), then postnasal drip (33 cases, 34.4\%) and anosmia (23 cases, $24.0 \%$ ). Other manifestations included: epistaxis, facial pain, otolgic symptom, visual problem and toothache in $8(8.3 \%), 8$ $(8.3 \%), 4(4.2 \%), 3(3.1 \%)$ and $3(3.1 \%)$, respectively.

The radiological findings of some patients have been demonstrated in figures 3 through 5 . 


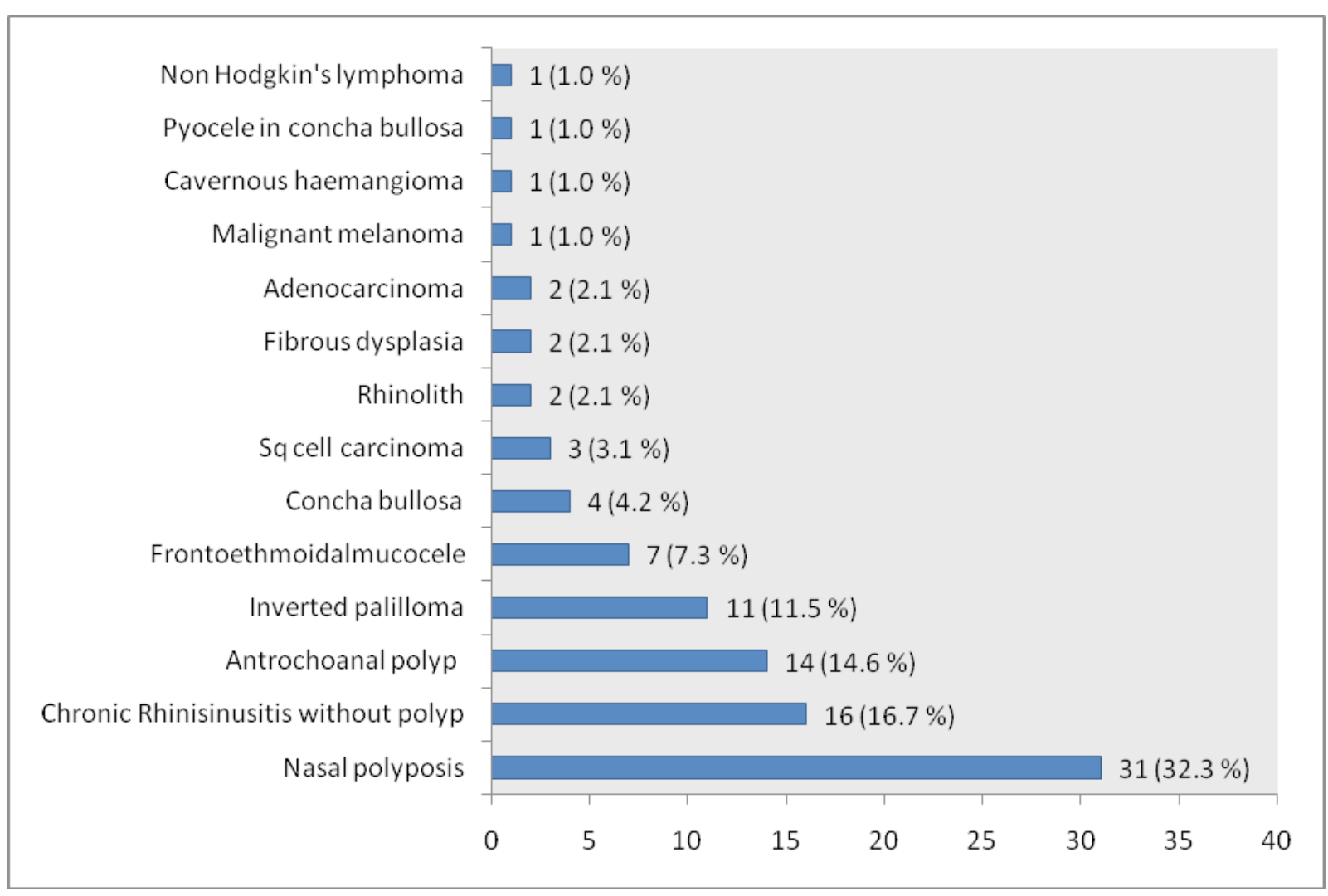

Figure 1: Bar chart showing the frequency distribution of patients with unilateral nasal disease according to etiology

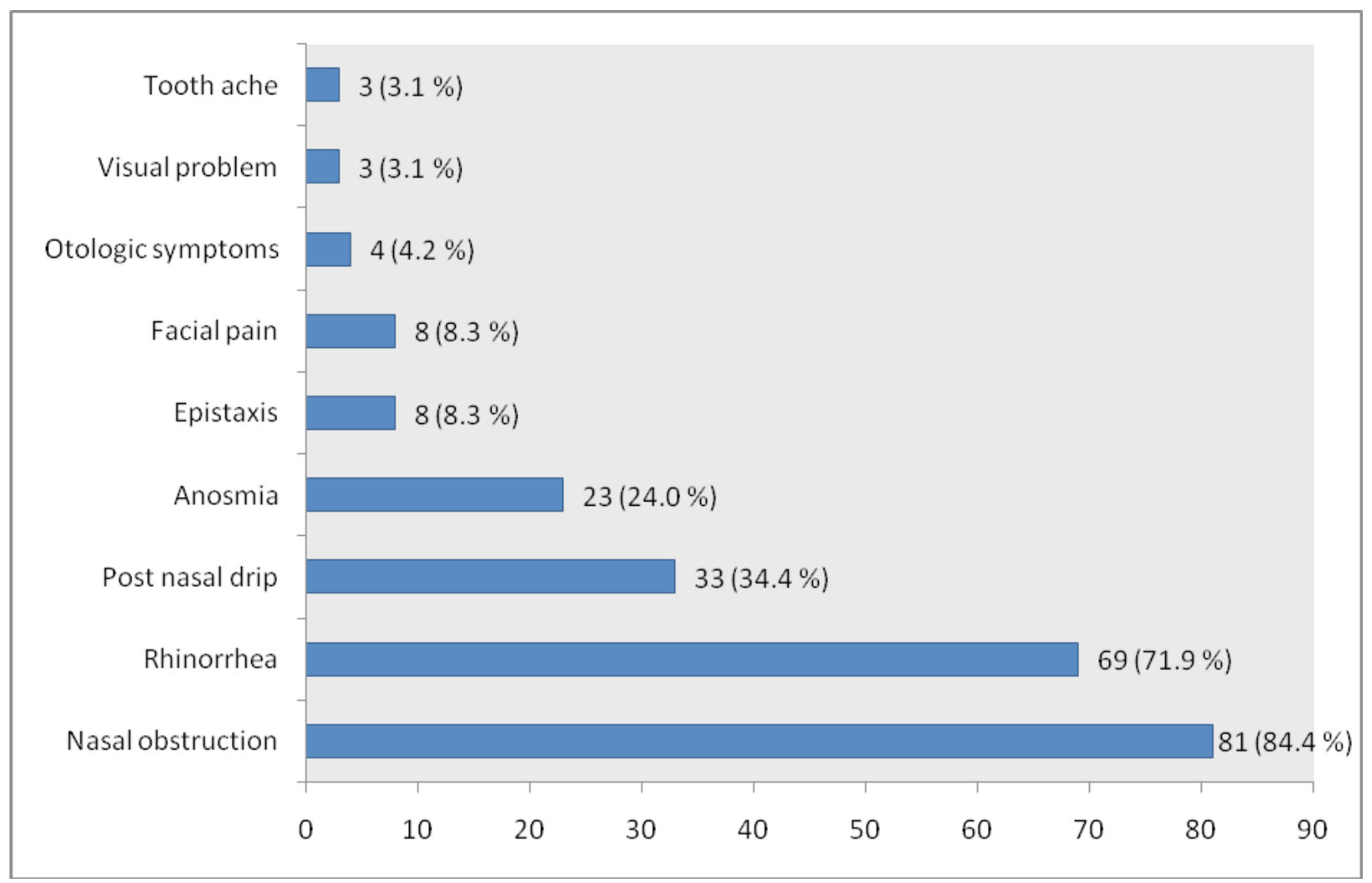

Figure 2: Bar chart showing the frequency distribution of patients with unilateral nasal disease according to clinical features 


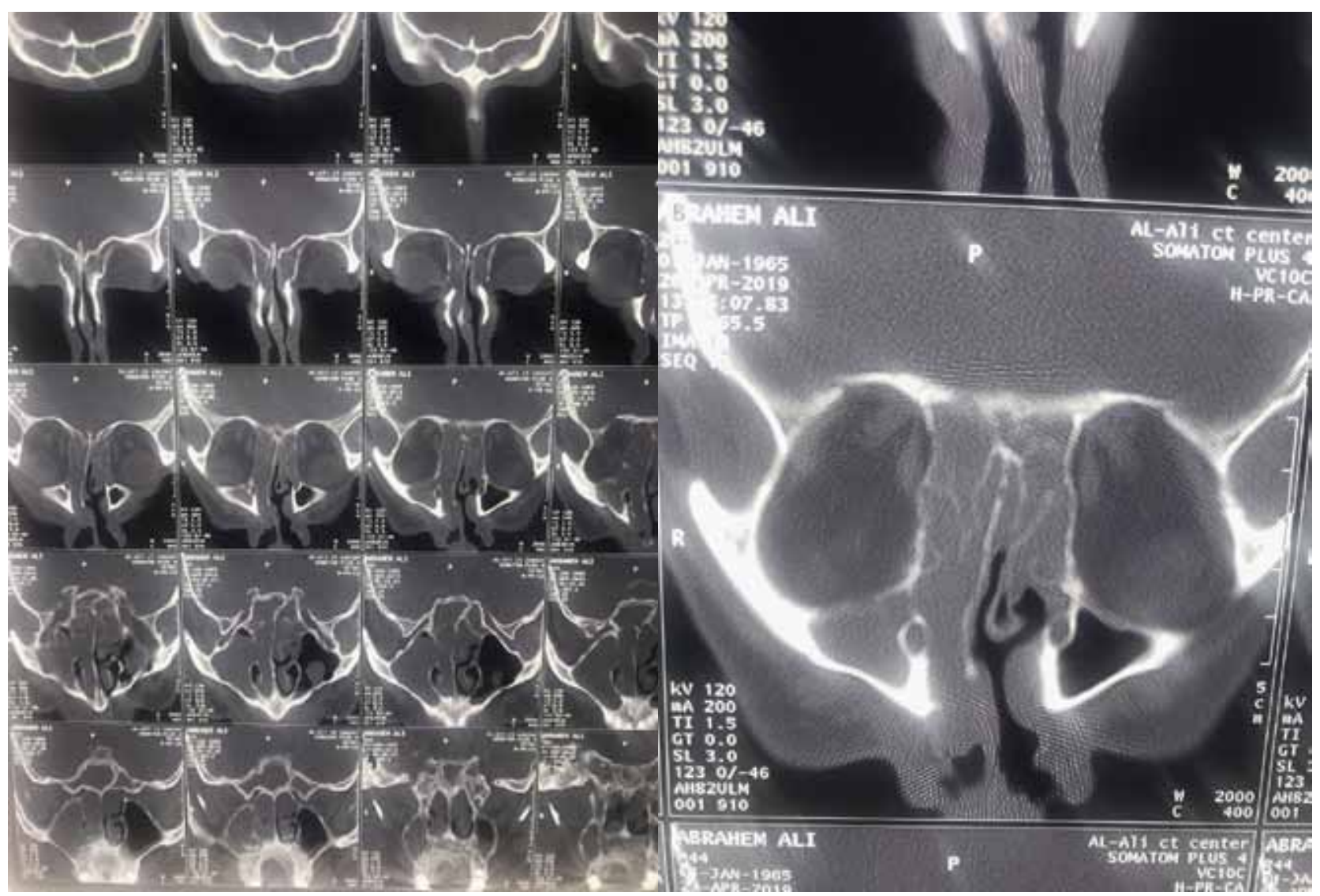

Figure 3: Computed tomogram findings in a patient with unilateral chronic rhinosinusitis

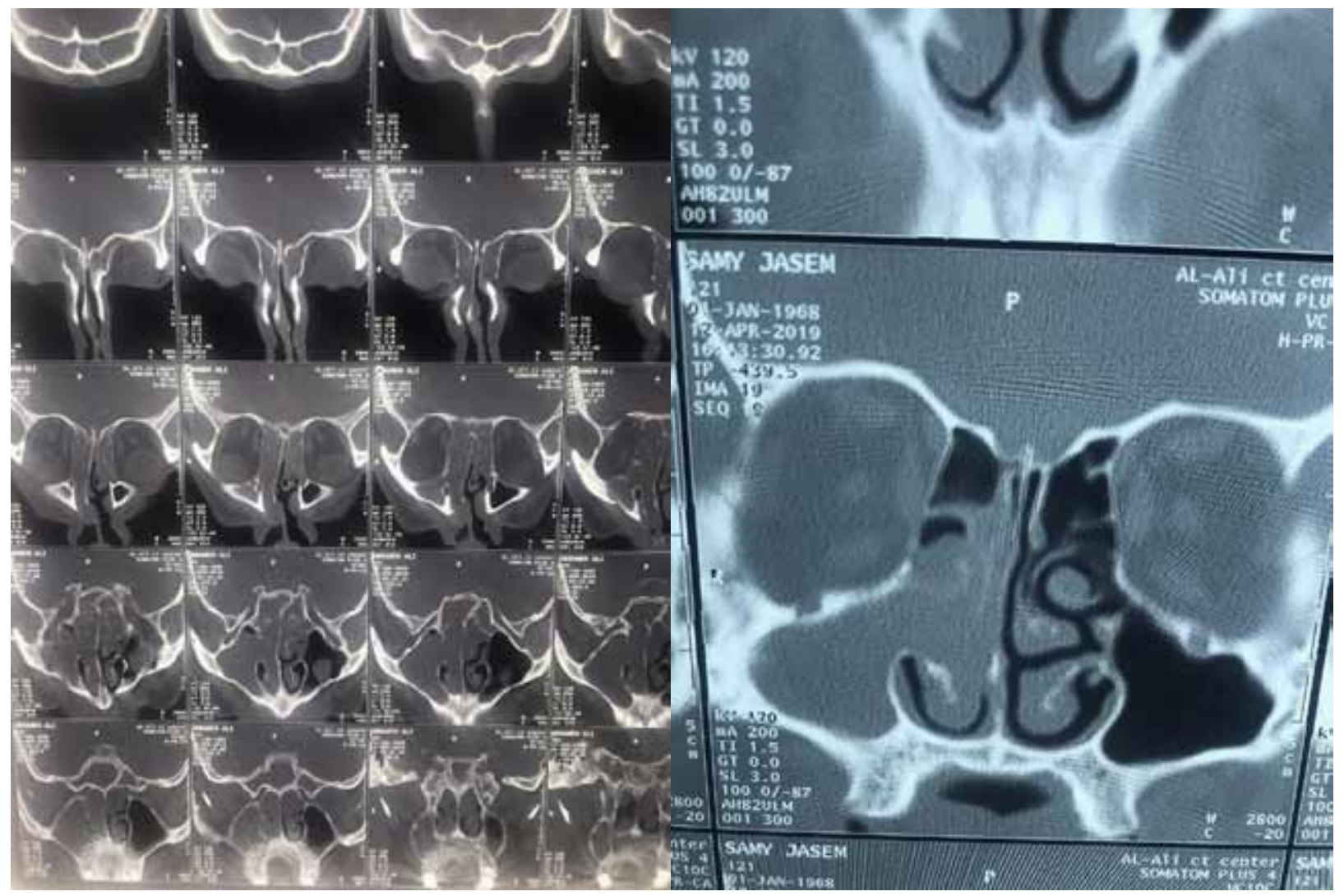

Figure 4: Computed tomogram findings in a patient with unilateral nasal polyposis 


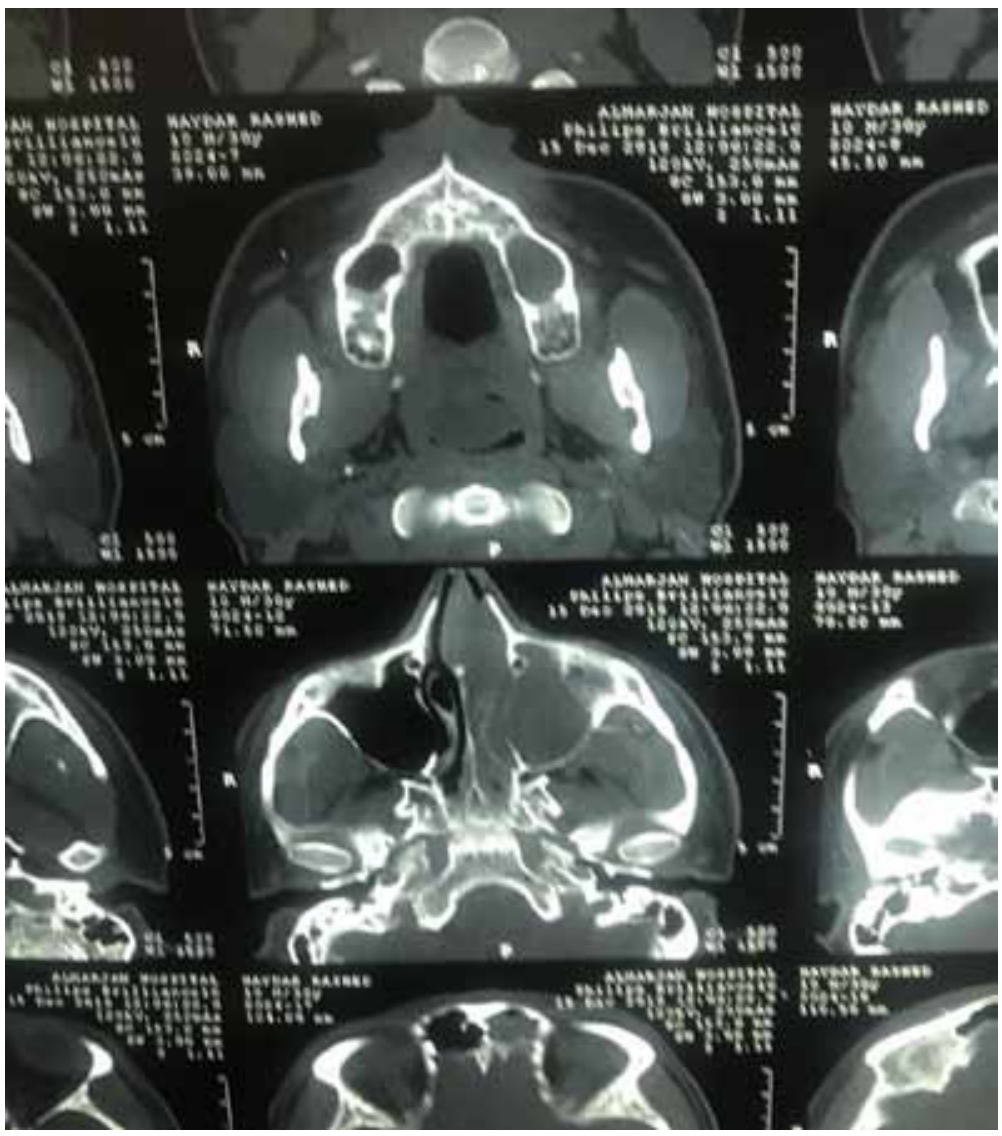

Figure 5: Axial view patient with unilateral nasal disease

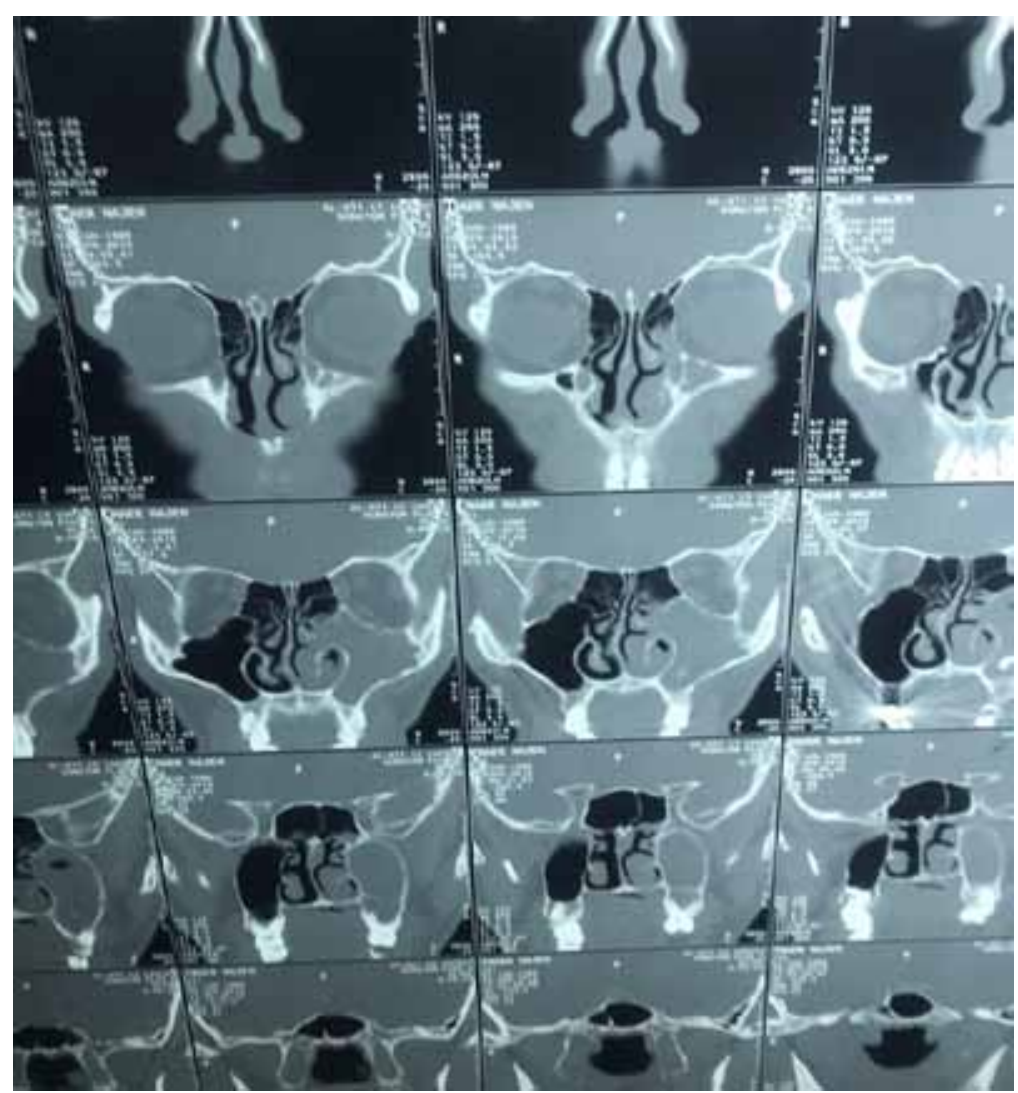

Figure 6: Computed tomogram findings in a patient with antrochoanal polyp 


\section{Discussion}

One of the frequent presenting features of patients visiting ENT units is the complaint of unilateral nasal problems. Indeed, it is a challenging presentation to the ENT specialist because of the high possibility of a neoplastic disorder to be seen in association with unilateral nasal presentation than with bilateral nasal presentation; however, overall, the proportion of neoplastic disorders is low in either presentation ${ }^{11,12}$.

In the current study, which has extended for more than 3 years, we were able to categorize 96 patients with unilateral nasal disease. The most frequent pathologies were nasal polyposis, chronic rhinosinusitis without polyp, antrochoanal polyp and inverted papilloma. In order to accomplish this mission, we followed the rule of comprehensive clinical evaluations of patient's age, presenting clinical features, examination using nasoendoscopy, and radiological investigations, computed tomography $(\mathrm{CT})$ in particular. In accordance with current study findings, it has been stated that the majority of pathologies in the sinonasal region are reactive inflammatory disorders and that the minority of them are neoplastic disorders ${ }^{12}$.

The problem with neoplastic malignant sinonasal pathologies is that they mimic inflammatory disorders in their early stages, so that the diagnosis of these disorders is often made late. Delay in the diagnosis of such malignant disorders is usually accompanied by poor prognosis; therefore, meticulous evaluation of unilateral nasal presentations is of prime importance to exclude malignant neoplastic disorders ${ }^{1}$.

With respect to age, benign neoplasms are often seen in children and young adults (1). The average age at time of detecting unilateral choanal polyps is around 27 (13). Fifth to $7^{\text {th }}$ decade is the usual time for detecting neoplastic disorders in patients with sinonasal disorder with a male predominance and low socioeconomic status ${ }^{14}$. Indeed, one of principal observations in the current study was that males were more often affected by neoplastic disorders than women and that inflammatory conditions were mainly seen in younger patients.

A variety of clinical manifestations are associated with unilateral nasal lesions, such as nasal discharge, nasal obstruction, anosmia, headache and epistatxis. In the current study the major presenting symptoms in order of frequency were nasal obstruction which was seen in 81 cases $(84.4 \%)$, followed by rhinorrhea ( 69 cases, $71.9 \%$ ), then postnasal drip (33 cases, 34.4\%) and anosmia (23 cases, 24.0\%). These findings are approximately the same as the findings of previous authors ${ }^{1}$.

Facial pain, dental complaint and visual and otologic manifestation have also been seen in our study in accordance with previous observations made by several authors ${ }^{1,4}$.

Comprehensive understanding of intranasal structure and characterization of intranasal pathologies have been made easy and amenable following the introduction of nasal endoscope ${ }^{1}$. Therefore, in the current study, the use of nasal endoscope provided both diagnostic and therapeutic tool since a number of conditions were treated by total excision of nasal pathology. The nasal mass lesions may be seen as single of multiple masses, sessile or pedunculated polyps.

Inflammatory conditions like acute and chronic CRS, either from bacterial or fungal origin were the commonest histopathological diagnosis in our study. Inflammation was the commonest form of nasal pathology in the current study and this is in accordance with previous reports ${ }^{1}$. In our study, the commonest benign neoplasm was inverted papilloma (11.5\%) and this finding is supported by previous similar findings 1,15 . On the other hand, the most common malignant neoplasm in our study was squamous cell carcinoma which is the same observation as the observation of some previous authors ${ }^{1,16}$. In our study, a single case of Non-Hodgkin lymphoma was identified. Previous studies have also documented the rarity of Non-Hodgkin lymphoma in this clinical setting ${ }^{1,17}$.

\section{Conclusion}

Differentiating the neoplastic nature form nonneoplastic nature of unilateral nasal pathology is the most critical management step and in the current study, nasal polyposis was the commonest cause of unilateral sinonasal disease followed by chronic rhinosinusitis without polyp, antrochoanal polyp and inverted papilloma. The rate of neoplastic malignant conditions was low.

Acknowledgement: We would like to express our deep thanks to all patients who participated in the current study to be a baseline report about the anatomical and the pathological presentation of unilateral sinonasal disease in Iraq. 
Financial Disclosure: There is no financial disclosure.

Conflict of Interest: None to declare.

Ethical Clearance: All experimental protocols were approved under the Department of Surgery and all experiments were carried out in accordance with approved guidelines.

\section{References}

1. Nair S, James E, Awasthi S, Nambiar S, Goyal S. A review of the clinicopathological and radiological features of unilateral nasal mass. Indian $\mathrm{J}$ Otolaryngol Head Neck Surg. 2013;65(Suppl 2):199-204.

2. Kaplan BA, Kountakis SE. Diagnosis and pathology of unilateral maxillary sinus opacification with or without evidence of contralateral disease. Laryngoscope. 2004;114:981-985.

3. Karthikeya P, Mahima VG, Bhavna G. Sinonasal verrucous carcinoma with oral invasion. Indian $\mathbf{J}$ Dent Res. 2006;1(7):82-86.

4. Tritt S, McMains KC, Kountakis SE. Unilateral nasal polyposis: clinical presentation and pathology. Am J Otolarygol Head Neck Med Surg. 2008; 29:230-232.

5. Iqbal SM, Hussain SI. Unilateral nasal obstruction caused by sino-nasal neoplastic lesions. Journal of the Liaquat University of Medical and Health Sciences. 2006; 5 (1): 18-23.

6. Chung HK, Tai CJ, Wang PC, Lin CD, Tsai $\mathrm{MH}$. Analysis of disease patterns in patients with unilateral sinonasal diseases. Mid Taiwan J Med. 2008; 13:82-88.

7. Belli S, Yildirim M, Eroglu S, Emre FK. Singlesided sinonasal mass: A retrospective study. North Clin Istanb. 2018;5(2):139-143.

8. Paz Silva M, Pinto JM, Corey JP, Mhoon EE,
Baroody FM, Naclerio RM. Diagnostic algorithm for unilateral sinus disease: a 15-year retrospective review. Int Forum Allergy Rhinol. 2015;5:590-6.

9. Habeşoğlu TE, Habeşoğlu M, Toros SZ, Naiboğlu B, Sürmeli M, Egeli E. Tek taraflısinonazal polipoid kitlelerde histopatoloji ve neoplastik için risk faktörleri. Göztepe Tıp Dergisi. 2010;25:7881.

10. Eckhoff A, Cox D, Luk L, Maidman S, Wise SK, DelGaudio JM. Unilateral versus bilateral sinonasal disease: Considerations in differential diagnosis and workup. Laryngoscope. 2020;130(4):E116-E121.

11. Lee JY. Unilateral paranasal sinus diseases: analysis of the clinical characteristics, diagnosis, pathology, and computed tomography findings. Acta Otolaryngol. 2008;128(6):621-626.

12. Euteneuer S, Sudhoff $\mathrm{H}$, Bernal-Sprekelsen $\mathrm{M}$, et al. Malignomas of the nasal cavity and the paranasal sinuses: clinical characteristics, therapy and prognosis of different tumour types. Laryngorhinootologie. 2004;83(1):33-39.

13. Larsen $\mathrm{K}$, Tos $\mathrm{M}$. The estimated incidence of symptomatic nasal polyps. Acta Otolaryngol. 2002;122:179-182.

14. Zbaren P, Richard JM, Schwaab G. Malignant neoplasms of the nasal cavity and paranasal sinuses. Analysis of 216 cases of malignant neoplasms of nasal cavity and paranasal sinuses. HNO. 1987;35(6):246-249.

15. Dammann F, Pereira P, Laniado M, et al. Inverted papilloma of the nasal cavity and the paranasal sinuses: using CT for primary diagnosis and followup. Am J Rhinol. 1999;172:543-548.

16. Gullane PJ, Conley J. Carcinoma of the maxillarysinus. J Tolaryngol. 1983;12:141-145.

17. Nowara E, Szelc S, Syguła D, Plewicka M, Przeorek W. Primary non-Hodgkin's lymphoma of the maxillary sinus. Otolaryngol Pol. 1997;51(4):418421. 